\title{
Population-Based Effects of Mammography Screening in Bavaria on the Distribution of TNM-T Categories with Respect to Different Histological Subgroups
}

\author{
Ulrike Braisch Karla Geiss Martin Radespiel-Tröger Martin Meyer \\ Population-Based Cancer Registry Bavaria, Erlangen, Germany
}

\section{Keywords}

Mammography - Screening - Breast cancer . Histological types

\section{Summary}

Background: Organized mammography screening was implemented in Bavaria in 2003, with a target population of about 1.5 million women (aged 50-69 years). We evaluated the population-based effects of mammography screening on the distribution of tumor-nodemetastasis (TNM)-T categories with regard to different histological subgroups of breast cancer. Patients and Methods: Women diagnosed with breast cancer between 2002 and 2008 were included. The annual agespecific incidence rates separated by $T$ category were calculated for different histological subgroups and plotted against time. Time trends were analyzed not only in the screening population but also based on women aged $15-49$ and $\geq 70$ years, respectively. Furthermore, correlation coefficients were calculated in order to evaluate the possible association between participation rate and incidence of certain TNM-T categories. Results: With ductal carcinomas, the incidence of early-stage tumors shows a strong increase in the screening population and a significant correlation with the participation rate, whereas with lobular carcinomas there is a stagnation of incidence in women aged 50-69 years irrespective of TNM-T category. Conclusions: Short-term effects of mammography screening can already be demonstrated. However, depending on breast cancer type, not all women appear to benefit from screening. The expected long-term reduction of breast cancer mortality remains to be seen.

\author{
Schlüsselwörter \\ Mammographie · Screening · Brustkrebs . \\ Histologietypen
}

\section{Zusammenfassung}

Hintergrund: Ein organisiertes Mammographie-Screening wurde in Bayern mit einer Zielbevölkerung von ungefähr 1,5 Millionen Frauen (50-69-Jährige) im Jahr 2003 eingeführt. Die bevölkerungsbezogenen Auswirkungen des Mammographie-Screenings auf die Verteilung der TNM-T-Kategorien (TNM = tumor-nodemetastasis) wurden in verschiedenen histologischen Brustkrebs-Untergruppen analysiert. Patientinnen und Methoden: Ausgewertet wurden Brustkrebsdiagnosen zwischen 2002 und 2008. Jährliche altersspezifische Inzidenzraten wurden für verschiedene histologische Untergruppen getrennt nach T-Kategorie berechnet und grafisch dargestellt. Trends wurden nicht nur innerhalb der Screening-Population analysiert, sondern auch für Frauen im Alter von 15-49 Jahren und $\geq 70$ Jahren. Zusätzlich wurden Korrelationskoeffizienten berechnet, um mögliche Beziehungen zwischen Teilnahmerate und Inzidenz bestimmter T-Kategorien aufzudecken. Ergebnisse: Bei duktalen Karzinomen weist die Inzidenz von Tumoren im Frühstadium einen starken Anstieg in der Screening-Population und eine signifikante Korrelation zur Teilnahmerate auf, wohingegen bei lobulären Karzinomen ungeachtet der T-Kategorie eine Stagnation der Inzidenz bei 50-69-jährigen Frauen zu beobachten ist. Schlussfolgerungen: Kurzzeiteffekte des Mammographie-Screenings können schon beobachtet werden. Je nach Brustkrebstyp scheinen aber nicht alle Patientinnen vom Screening zu profitieren. Ob das MammographieScreening zur erwarteten langfristigen Reduktion der Brustkrebsmortalität führt, bleibt abzuwarten.

\section{KARGER}

Fax +497614520714

Information@Karger.de

www.karger.com (c) 2012 S. Karger GmbH, Freiburg

1661-3791/12/0074-0303\$38.00/0

Accessible online at:

www.karger.com/brc
Ulrike Braisch

Bevölkerungsbezogenes Krebsregister Bayern

Östliche Stadtmauerstr. 30, 91054 Erlangen, Germany

Tel. +49 9131 85-36063, Fax -36040

ulrike.braisch@gmx.de 


\section{Introduction}

Breast cancer is the most frequent cancer in women in Germany with regard to both incidence and mortality [1]. The World Health Organization (WHO) recommends screening programs for the early detection of breast cancer [2]. The main aim of the screening is the reduction of mortality due to breast cancer. Currently, for the target population (women aged 50-69 years), mammography screening is considered as the only method of early detection that can achieve this goal. Therefore, an organized, population-based and qualitysecured program is recommended $[3,4]$.

In Germany, all women aged 50-69 years are invited every 2 years to participate in the mammography screening program.

The Bavarian mammography screening (BMS) program was introduced in 2003. In 2006, it was transferred into the German mammography screening (GMS) program according to the European guidelines for quality assurance in breast cancer screening and diagnosis [5]. The population-based participation rate per year is given in table 1 . Since only about half of the target population is entitled to screening per year, the total screening participation rate within a 2-year screening interval is the sum of two 1-year-based participation rates.

The long-term effectiveness of the mammography screening has already been shown in several studies (e.g. [6-11]) which required a long observation time. Since in Bavaria the screening was introduced only in 2003 , the evaluation of the effectiveness of mammography screening is currently limited to short-term effects. Cancer mortality is strongly associated with the tumor size at the time of diagnosis [12]. Therefore, the tumor size can be used as surrogate criterion for the crude estimation of long-term prognosis of breast cancer.

This study examines population-based effects of mammography screening in different histological subgroups of breast cancer using the distribution of tumor-node-metastsis (TNM)$\mathrm{T}$ categories as crude estimate of the long-term prognosis.

\section{Material and Methods}

Generally, a completeness of cancer registration of at least $90 \%$ of the expected cases is required in order to achieve valid estimates of incidence [13]. In Bavaria, this prerequisite has been achieved in all years between 2003 and 2008 with respect to breast cancer in women. In 2002, the completeness of registration was $88 \%$. Since the TNM category distribution is usually stable with a registration completeness of at least $70 \%[14,15]$, the year 2002 was used to analyze the TNM-T category distribution prior to the implementation of mammography screening. Therefore, data related to breast cancer in women diagnosed between 2002 and 2008 were included in the present study. Cancer cases registered as 'death certificate only' (DCO) (all age groups: 7865 cases (11.2\%); 50-69 years: 1465 cases $(4.4 \%)$ ) cannot provide any staging information and were excluded from the analyses.

Age-specific incidence is given as rate per 100,000 women per year. Annual age-specific incidence rates separated by TNM-T category were calculated for different histological subgroups and plotted against time. Time trends were analyzed not only in the screening population but also in the 2 population groups of women aged 15-49 years and 70 years and above. Incidence rate differences were computed with regard to histological type, age group, and TNM-T category. The corresponding $95 \%$ confidence interval $(\mathrm{CI})$ was calculated based on a commonly used method [16].

Additionally, the frequency distribution of histological cancer types in the target population was computed.

Furthermore, correlation coefficients were calculated via analysis of covariance, thus accounting for repeated observations within screening units [17] in order to evaluate the possible association between the population-based participation rate and the distribution of TNM-T categories. Since the start of organized screening was in 2003, the participation rate was not measured in 2002. Therefore, the year 2002 was excluded from the computation of correlation coefficients. The respective $95 \%$ CIs were computed using the bias-corrected, accelerated (BCa) bootstrap [18].

All calculations were made using SPSS version 17 (SPSS Inc., Chicago, IL, USA), Microsoft Excel for Windows version 2002 (Microsoft Corp., Redmond, WA, USA), and the statistical software R version 2.11.1 (R Foundation for Statistical Computing, Vienna, Austria).

The number of cases of incident breast cancer $(n=62,572)$ with regard to different histological subgroups is given in table 2, together with the respective International Classification of Diseases for Oncology (third edition) (ICD-O-3) morphology codes [19].
Table 1. Population-based participation rate per year

Table 2. Number of breast cancer cases (DCO cases were excluded) diagnosed between 2002 and 2008 with regard to histological tumor type and respective morphology code according to ICD-O-3 and [20, 21]

\begin{tabular}{lccccccc}
\hline Year & 2002 & 2003 & 2004 & 2005 & 2006 & 2007 & 2008 \\
\hline Participation rate & - & $0.1 \%$ & $4.5 \%$ & $10.1 \%$ & $9.0 \%$ & $9.7 \%$ & $16.4 \%$ \\
\hline 2-year screening interval participation rates can be calculated as sum of two 1 -year-based rates. \\
\hline
\end{tabular}

\begin{tabular}{llc}
\hline Histological tumor type & Morphology code (ICD-O-3) & Cases, $\mathrm{n}$ \\
\hline DCIS & $8201 / 2,8230 / 2,8500 / 2,8501 / 2,8503 / 2,8507 / 2$ & 3,897 \\
LCIS & $8520 / 2$ & 215 \\
IDC & $8050 / 3,8201 / 3,8211 / 3,8260 / 3,8480 / 3,8500 / 3,8501 / 3$, & 44,977 \\
& $8503 / 3,8504 / 3,8510 / 3,8512 / 3,8513 / 3,8521 / 3,8525 / 3$ & \\
ILC & $8520 / 3$ & 7,603 \\
Other & - & 2,894 \\
Unknown & $8000 / 3,8010 / 2,8010 / 3$ and missing morphology code & 2,986 \\
Sum & & 62,572 \\
\hline DCO = Death certificate only, DCIS = ductal carcinoma in situ, LCIS = lobular carcinoma in situ, \\
IDC = invasive ductal carcinoma, ILC = invasive lobular carcinoma. \\
\hline
\end{tabular}




\section{Results}

The size of the female Bavarian population in the year 2002 and the number of breast cancer cases according to different age groups are given in table 3 .

In figure 1, the frequency distribution of histological tumor types is plotted against time with respect to women aged 50-69 years. While the percentage of ductal carcinoma in situ (DCIS) increased steadily, the percentage of lobular carcinoma in situ (LCIS) hardly changed. Invasive ductal carcinoma (IDC) showed only a small increase. On the other hand, the percentages of invasive lobular carcinoma (ILC) decreased during the study period.

The most frequent types of breast cancer are ductal carcinoma (IDC, DCIS) and lobular carcinoma (ILC, LCIS), which accounted for $88.5 \%$ of all breast tumors in 2002 and for $93.7 \%$ in 2008 , respectively.

\section{Ductal Carcinoma}

With an initial percentage of $74 \%$ in the year 2002 , the ductal carcinoma (including DCIS) is the most frequent tumor type in breast cancer patients. Thus, the effects of mammography screening on this type will have a big impact on the overall effects.

The trends of the TNM-T stages for ductal tumors for women aged 50-69 years are displayed in figure 2. Early stages (in situ and invasive tumors $<1 \mathrm{~cm}$ ) strongly increased, whereas the incidence of the TNM-T categories T1c, T1x, and $\mathrm{T} 2$ as well as the total incidence initially increased until 2005, followed by a decrease between 2005 and 2007, and increased afterwards once more. To date, no obvious trend could be observed with the T3- and T4-staged tumors.
If TNM-T category shifts in the target population (women aged 50-69 years) are due to screening, these category shifts should be absent in the 2 other age groups (15-49 and $\geq 70$ years). We therefore compared the time trends of incidence in the screening population with those in women aged 15-49 years and in women aged $\geq 70$ years. In the screening population, the incidence of ductal carcinomas with the TNM-T categories Tis, T1mic, T1a, and T1b (fig. 3) strongly rose from 40 to 86 cases per 100,000 women per year. The incidence stagnation between 2005 and 2007 may possibly be attributed to the transition from the BMS to the GMS program, which caused a stagnation in the invitation process. In women older or younger than the screening population, only a small increase in cancer incidence between 2003 and 2005 was observed, without any relevant change afterwards.

The impact of screening on the incidence of early-stage tumors in the screening population was further assessed by calculating the correlation between participation rate and incidence of tumors with the TNM-T categories Tis, T1mic, T1a, and T1b. For ductal carcinomas, we found a strong positive correlation (r, 0.85; 95\% CI, 0.71-0.90).

The age-specific incidence of invasive tumors with a size of at least $10 \mathrm{~mm}$ (TNM-T categories T1c, T1x,T2, T3 and $\mathrm{T} 4)$ in the screening population rose from 142 to 161 cases per 100,000 women per year between 2002 and 2008, with a decline between 2005 and 2007 (fig. 3). For these TNM-T categories, we identified a moderate positive correlation of 0.33 (95\% CI, 0.03-0.58). By contrast, the incidence in women aged 15-49 years was nearly constant. In women aged 70 years and above, we observed a notable increase in incidence from 2002 to 2005 and a slight decrease afterwards. The rise in both upper age groups may be due to the
Table 3. Size of female population in Bavaria in the year 2002 and number of cases of breast cancer included in this study, in different age groups

Fig. 1. Frequency distribution of histological tumor types in women aged 50-69 years plotted against time (BMS: Bavarian mammography screening, GMS: German mammography screening).

\begin{tabular}{lrrrr}
\hline & $15-49$ years & $50-69$ years & $>$ 69 years & Total \\
\hline Female population in 2002 & $2,962,737(47 \%)$ & $1,472,217(23 \%)$ & $911,694(14 \%)$ & $6,313,308$ \\
Included breast cancer cases & $12,752(20 \%)$ & $31,896(51 \%)$ & $17,924(29 \%)$ & 62,572 \\
\hline
\end{tabular}

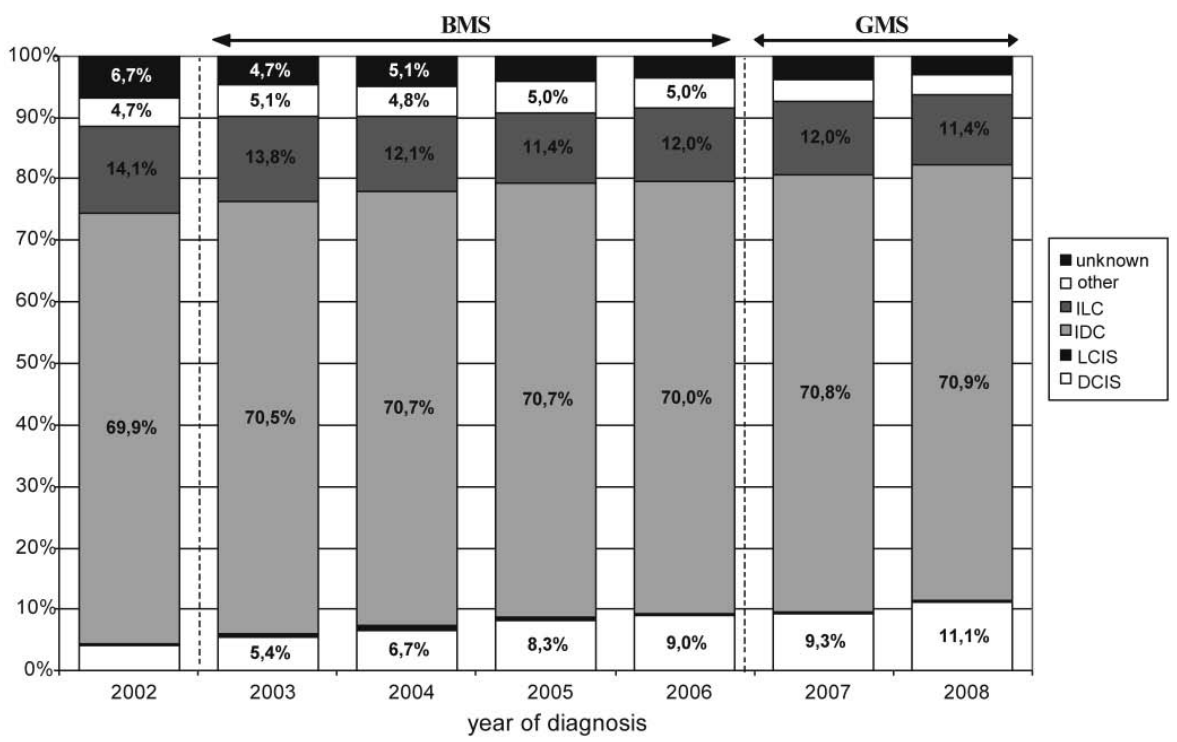


increasing registration completeness in the respective time period.

\section{Lobular Carcinoma}

The lobular carcinoma is the second most frequent type of breast cancer and accounted for almost $15 \%$ of (in situ and invasive) breast carcinomas in 2002. We therefore assessed the annual incidence of this tumor type separated by TNM-T category (fig. 2) in women aged 50-69 years. In contrast to the results obtained in ductal carcinomas and regardless of TNM-T category, we did not observe any relevant changes in the incidence rate. Likewise, in the other 2 age groups, neither for early stages (in situ and invasive tumors below a size of $1 \mathrm{~cm}$ ) (fig. 3) nor for advanced tumors (invasive tumors above a size of $1 \mathrm{~cm}$ ) (fig. 3) a relevant time trend of the incidence rate was observed.

As expected, we did not find a relevant association between participation rate and incidence rate of lobular carcinomas, for both early-stage tumors (r, 0.07; 95\% CI, 0.00-0.25 ( $\mathrm{r}$ significantly different from zero)) and advanced tumors (r, 0.12; 95\% CI, 0.00-0.35 ( $\mathrm{r}$ significantly different from zero)). This result appears to underline the missing impact of mammography screening on the incidence (and hence, the detection) rate of lobular carcinomas in Bavaria.

\section{Summary}

A summary of the project results is given in table 4. For the observation period of 2003-2008 - from the implementation of screening till the end of the study - the incidence rate differences were calculated for different age groups, prognostically favorable and advanced tumors, and the most frequent histological tumor types.

\section{Discussion}

\section{Ductal Carcinomas}

Ductal carcinomas occur in the milk ducts (latin: ductus lactiferi) of the breast. Ductal carcinomas often possess calcifications, which are usually well recognizable in a mammogram [3]. Therefore, ductal carcinomas are expected to be easily detected by mammography screening.

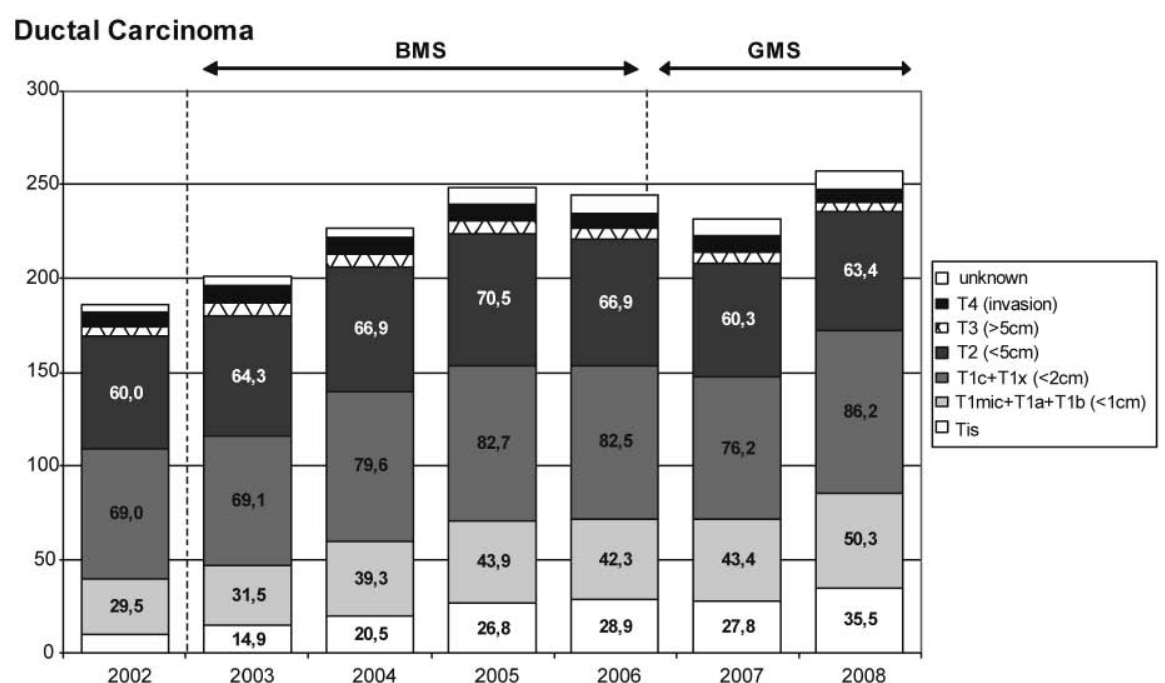

Lobular Carcinoma

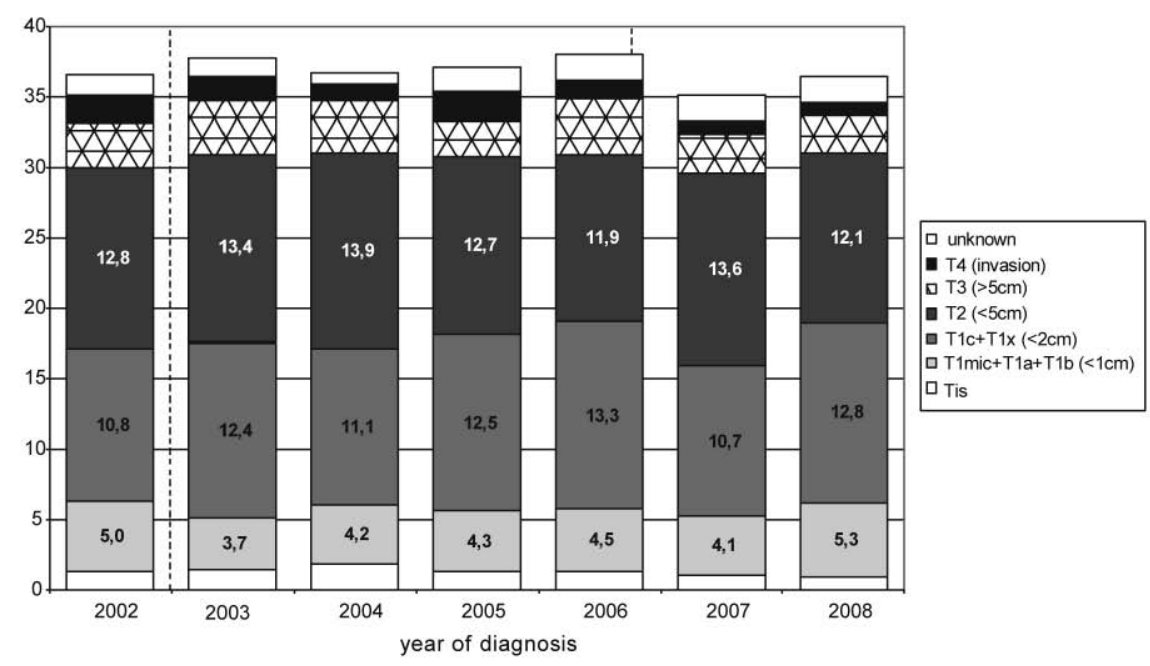

Fig. 2. Age-specific incidence (rates per 100,000 women per year) of ductal and lobular carcinoma plotted against time, separated by TNM-T category in women aged 50-69 years. 
Fig. 3. Age-specific incidence (rates per 100,000 women per year) of ductal and lobular carcinomas with TNM-T categories Tis, T1mic, T1a, T1b and T1c, T1x, T2, T3, T4 plotted against time, separated by age group.
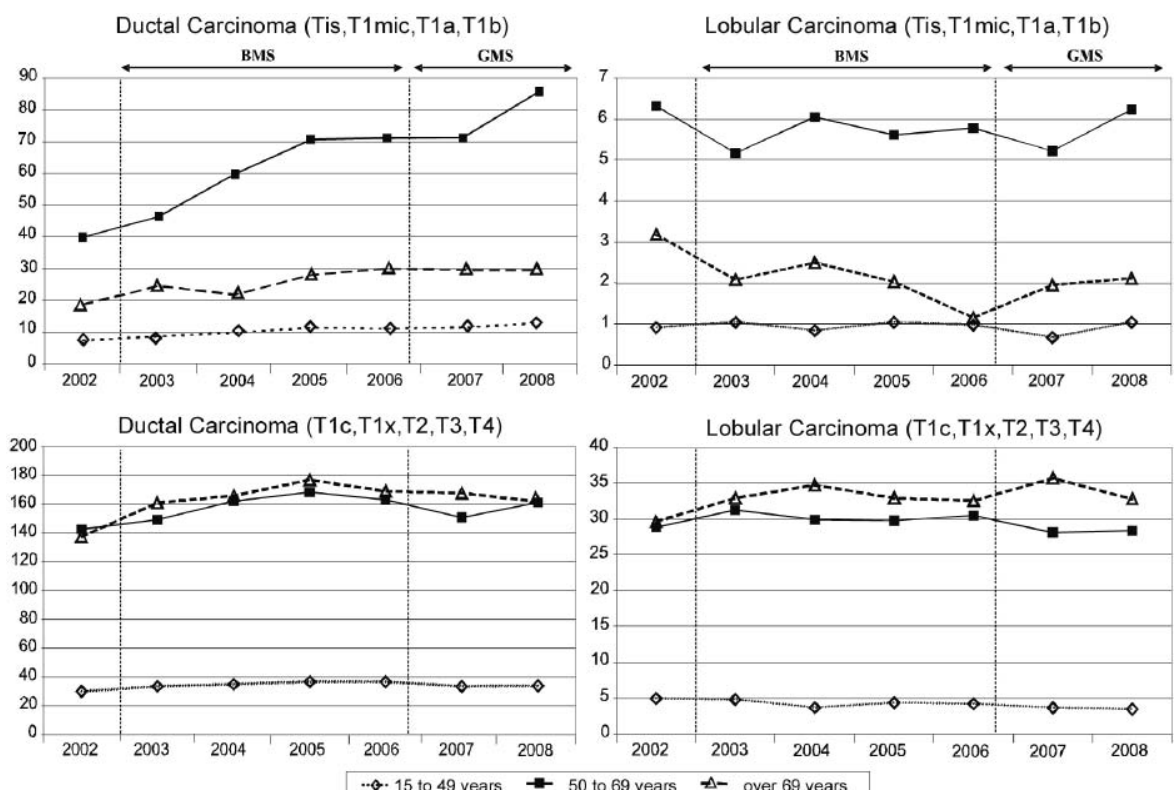

Table 4. Incidence rates in 2003 and 2008, and incidence rate differences with regard to histological tumor type, TNM-T category, and age group

\begin{tabular}{clccl}
\hline TNM-T category & Age group & $\begin{array}{l}\text { Incidence rate } \\
\text { (n/Pop) in 2003 }\end{array}$ & $\begin{array}{l}\text { Incidence rate }^{\mathrm{a}} \\
\text { (n/Pop) in 2008 }\end{array}$ & $\begin{array}{l}\text { Incidence rate difference }^{\mathrm{a}} \\
2003-2008(95 \% \mathrm{CI})\end{array}$ \\
\hline Ductal carcinoma & & & & \\
Tis, T1mic, T1a, T1b & $15-49$ & $8.7(259 / 2,972,951)$ & $12.8(380 / 2,969,153)$ & $+4.1(2.4 ; 5.8)$ \\
& $50-69$ & $46.4(692 / 1,490,907)$ & $85.8(1,322 / 1,541,271)$ & $+39.4(33.6 ; 45.1)$ \\
& $>69$ & $24.6(225 / 914,379)$ & $29.6(294 / 994,562)$ & $+5.0(0.3 ; 9.6)$ \\
T1c, T1x, T2, T3, T4 & $15-49$ & $33.4(993 / 2,972,951)$ & $33.8(1,002 / 2,969,153)$ & $+0.4(-2.6 ; 3.3)$ \\
& $50-69$ & $149.2(2,225 / 1,490,907)$ & $161.2(2,485 / 1,541,271)$ & $+12.0(3.1 ; 20.9)$ \\
Lobular carcinoma & $>69$ & $161.1(1,473 / 914,379)$ & $161.9(1,610 / 994,562)$ & $+0.8(-10.6 ; 12.2)$ \\
Tis, T1mic, T1a, T1b & $15-49$ & $1.0(31 / 2,972,951)$ & $1.0(31 / 2,969,153)$ & $0.0(-0.5 ; 0.5)$ \\
& $50-69$ & $5.2(77 / 1,490,907)$ & $6.2(96 / 1,541,271)$ & $+1.1(-0.6 ; 2.8)$ \\
T1c, T1x, T2, T3, T4 & $15-49$ & $2.1(19 / 914,379)$ & $2.1(21 / 994,562)$ & $0.0(-1.3 ; 1.3)$ \\
& $50-69$ & $4.8(142 / 2,972,951)$ & $3.4(102 / 2,969,153)$ & $-1.3(-2.4 ;-0.3)$ \\
& $>69$ & $31.3(466 / 1,490,907)$ & $28.4(437 / 1,541,271)$ & $-2.9(-6.8 ; 1.0)$ \\
\end{tabular}

${ }^{a}$ Per 100,000 women per year.

$\mathrm{CI}=$ Confidence interval, $\mathrm{n}=$ number of observed cases, $\mathrm{Pop}=$ population size .

In contrast to women aged 15-49 and 70+ years, our results demonstrate an approximate doubling of the incidence of DCIS and invasive carcinoma with a size of less than $10 \mathrm{~mm}$ in women aged 50-69 years between 2003 and 2008.

We also evaluated incidence trends in the narrower age groups 30-49 (instead of 15-49), 50-54, 55-59, 60-64, and 65-69 (instead of 50-69) years. We identified a larger increase in incidence of early-stage tumors in the age groups 60-64 and 65-69 years compared to the age groups 50-54 and 55-59 years (results not shown). However, in the age group 30-49 years, a similar trend was observed as in the age group 15-49 years.

With regard to tumors with a size of $10 \mathrm{~mm}$ and above (TNM-T categories: T1c, T1x, T2, T3, and T4), the incidence in women aged 50-69 years rose until 2005, followed by a fluctuation. By contrast, without significant trend, the respective incidence stagnated in women aged 15-49 years, whereas the incidence in women aged 70+ years increased until 2005 (possibly due to increasing registration completeness) and decreased slightly afterwards.

Initially, after the introduction of mammography screening, the detection (and incidence) rate of ductal carcinomas can be expected to rise regardless of tumor size, which is what we observed. After some years, however, small (i.e., newly developed) tumors are on average detected more frequently than larger tumors (which on average may have already been detected during previous screening rounds). Hence, the incidence rate of larger tumors is expected to drop several years after the introduction of screening. However, the observation period of this study is too small to observe such a decline attributed to screening, and which remains to be seen.

\section{Lobular Carcinomas}

Lobular carcinomas occur in the glandular lobules of the breast. It is difficult to distinguish lobular carcinomas from the tissue of origin because they usually possess no typical 
mammographic features such as calcifications [3]. For this reason, they are only detected infrequently by mammographic screening, which in turn leads to frequent false-negative findings [3]. Therefore, LCIS are commonly detected as an incidental finding in a biopsy resulting from a mammographic abnormality or a palpable mass [3, 22].

With regard to the incidence rates of lobular carcinomas, no relevant time trends were noted in all age groups, regardless of TNM-T category.

Based on our results, it can therefore be concluded that lobular breast cancers escape mammographic detection quite often, so that organized mammography screening currently does not influence the detection rate and the incidence of lobular carcinoma in Bavaria.

\section{Comparison of Results with Existing Literature}

Previous reports from Sweden and Geneva (Switzerland) also showed an increased incidence of in situ and invasive ductal breast cancers due to mammography screening [23, 24]. In the Southern Netherlands, the incidence of DCIS increased markedly in women aged 50-69 years since the introduction of screening in 1992, and with a time lag of 6 years in women aged 70-75 years, whereas the screen-detected incidence paralleled the overall incidence [25].

Likewise, in Sweden, the incidence of LCIS did not change over time [23], but unlike our results, a slightly increased incidence of invasive lobular breast cancers was demonstrated [23]. In Geneva, a sharp rise in the incidence of ILC was indeed shown, but this was present in all age groups and therefore was presumably caused by other factors than mammography screening [24].

Furthermore, in view of the overall breast cancer incidence, in a Swedish randomized trial in Östergötland, the incidence strongly increased in the group invited to mammography screening in comparison to the control group and decreased to the same incidence as in the control group after the end of the screening trial [11].

In Germany, based on the evaluation report of the nationwide screening program for the years 2005-2007, considerably higher (lower) percentages of early-stage (advanced) tumors were noted in the screening participants compared with the reference population [26].

\section{Limitations of Our Study}

The validity of our results is limited by a number of factors.

Firstly, individual pieces of information about invitation and participation status were not available at the PopulationBased Cancer Registry Bavaria. Thus, unfortunately, no comparison between screened and non-screened breast cancer patients was possible with regard to the distribution of TNM-T categories.

Secondly, no data is currently available on the rate of mammographic screening outside of the official screening program (i.e., opportunistic screening). In particular, opportu- nistic screening can be assumed to increase the incidence of breast cancer in women aged below 50 or above 70 years of age. Furthermore, due to the lack of measures of quality assurance in opportunistic screening, it can be expected to lead to an increased rate of false-negative diagnoses, regardless of the age group. Therefore, opportunistic screening will tend to downward bias the estimates of the screening effectiveness.

Thirdly, an increased public awareness of breast cancer stimulated by increased media coverage may lead to an increased rate of self-examinations and consultations with doctors, with a possible consecutive increase in the number of breast cancer diagnoses, which in turn would also downward bias the estimates of the effectiveness of the official screening program.

Fourth, the increasing completeness of breast cancer registration in Bavaria between 2003 and 2005 may have led to an apparently increased breast cancer incidence among all age groups in that time period, which in turn may have biased the estimates of the effectiveness of the screening program.

Fifth, the insufficient completeness of registration of breast cancer in Bavaria prior to 2002 limits the available sample size for the estimation of the TNM-T category distribution prior to the introduction of the screening program, thus reducing the precision of the obtained estimates.

\section{Conclusions}

Despite the discussed limitations, short-term effects of organized mammography screening, based on the observed TNM-T category shifts, can already be demonstrated for ductal carcinomas, which tend to be diagnosed at earlier stages.

However, our results also demonstrate remarkable differences between the different histological tumor types. While the ductal carcinoma offers a good detectability, the lobular carcinoma is only rarely recognized by mammographic screening. We conclude that mammographic screening does not detect all histologic tumor types with sufficient reliability.

An evaluation of the breast cancer mortality in Germany in view of the effect of mammography screening is in preparation.

\section{Acknowledgements}

Supported by the Deutsche Krebshilfe (German Cancer Aid). Special thanks go to all institutions and the respective staff members who made this work possible by providing valuable data: The 6 Bavarian clinical cancer registries in Augsburg (Schenkirsch G), Bayreuth (Maisel T), Erlangen-Nürnberg (Petsch S), Munich (Schrodi S, Hölzel D, Engel J), Regensburg (Klinkhammer-Schalke M) and Würzburg (Mäder U), and the Bavarian screening reference center Munich (Heywang-Köbrunner S).

\section{Disclosure Statement}

The authors declare no conflict of interest. 


\section{References}

1 Robert Koch Institute (eds), Association of Population-Based Cancer Registries in Germany (eds) Cancer in Germany 2005/2006. Incidence and Trends, ed 7. Berlin, Robert Koch Institute, 2010.

2 World Health Organization (WHO): www.who.int/ cancer/detection/breastcancer/en/index.html, 28 October 2010.

3 International Agency for Research on Cancer (IARC): Breast Cancer Screening, IARC Handbooks of Cancer Prevention, vol 7. Lyon, IARC Press, 2002.

4 International Agency for Research on Cancer (IARC): World Cancer Report 2008. Lyon, IARC Press, 2008

5 Perry N, Broeders M, de Wolf C, Törnberg S, Holland R, von Karsa L: European Guidelines for Quality Assurance in Breast Cancer Screening and Diagnosis, ed 4. Luxembourg, Office for Official Publications of the European Communities, 2006. www.mammo-programm.de/service/infomaterialfachservice.php.

6 Anderson WF, Jatoi I, Devesa SS: Assessing the impact of screening mammography: Breast cancer incidence and mortality rates in Connecticut (1943-2002). Breast Cancer Res Treat 2006; 99:333-340.

7 Hakama M, Pukkala E, Heikkilä M, Kallio M: Effectiveness of the public health policy for breast cancer screening in Finland: population based cohort study. BMJ 1997;314:864-872.

$>8$ Olsen AH, Njor SH, Vejborg I, Schwartz W, Dalgaard P, Jensen MB, Tange UB, Blichert-Toft M, Rank F, Mouridsen H, Lynge E: Breast cancer mortality in Copenhagen after introduction of mammography screening: cohort study. BMJ 2005;330:220-224.

9 Shapiro S, Venet W, Strax P, Venet L, Roesner R: Ten- to fourteen-year effect of screening on breast cancer mortality. L Natl Cancer Inst 1982;69:349_ 355.
10 Tabar L, Yen MF, Vitak B, Chen HH, Smith RA, Duffy SW: Mammography service screening and mortality in breast cancer patients: 20-year followup before and after introduction of screening. Lancet 2003;361:1405-1410.

11 Nyström L, Andersson I, Bjurstam N, Frisell J, Nordenskjöld B, Rutqvist LE: Long-term effects of mammography screening: updated overview of the Swedish randomised trials. Lancet 2002;359:909919.

12 Engel J, Eckel R, Aydemir U, Aydemir S, Kerr J, Schlesinger-Raab A, Dirschedl P, Hölzel D: Determinants and prognoses of locoregional and distant progression in breast cancer. Int $\mathrm{J}$ Radiat Oncol Biol Phys 2003;55:1186-1195.

13 Centers for Disease Control and Prevention: Registry Eligibility Criteria. http://wonder.cdc.gov/wonder/ help/cancer/USCS_2002_registry_eligibility_ criteria.html, 9 February 2011.

14 Katalinic A, Holzmann M, Kunze U: Abhängigkeit der Tumorstadien von der Vollzähligkeit der Registrierung bei Brustkrebs in einem bevölkerungsbezogenen Krebsregister. Gesundheitswesen 2003;65:509-515.

15 Radespiel-Tröger M, Geiss K, Gärtig-Daugs A, Meyer M: Registration completeness and tumournode-metastases category distribution in prostatic and testicular cancer in Bavaria. Eur J Cancer Prev 2008;17:230-237.

16 Rothman KJ: Modern Epidemiology. Boston/Toronto, Little, Brown and Company, 1986, pp 142f, $170 \mathrm{f}$.

17 Bland JM, Altman DG: Calculating the correlation coefficient with repeated observations. I. Correlation within subjects. BMJ 1995;310:446.

18 Venables WN, Ripley BD: Modern Applied Statistics with S. New York, Springer, 2002, pp 133-135.

19 Fritz A, Percy C, Jack A, Shanmugaratnam K, Sobin L, Parkin DM, Whelan S (eds): International Classification of Diseases for Oncology, ed 3. Geneva, World Health Organisation, 2000.
20 BreastCancer.org: Types of breast cancer. Less common subtypes of invasive ductal carcinoma. www.breastcancer.org/symptoms/types/rare_idc/, 15 February 2011.

21 Linda A, Zuiani C, Girometti R, Londero V, achin P, Brondani G, Bazzocchi M: Unusual malignan tumors of the breast: MRI features and pathologic correlation. Eur J Radiol 2010;75:178-184.

22 Goldschmidt RA, Victor TA: Lobular carcinoma in situ of the breast. Semin Surg Oncol 1996;12:314 320.

23 Rawal R, Bermejo JL, Hemminki K: Risk of s ubsequent invasive breast carcinoma after in situ breast carcinoma in a population covered by national mammographic screening. Br J Cancer 2005;92:162-166.

24 Verkooijen HM, Fioretta G, Vlastos G, Morabia A, Schubert H, Sappino AP, Pelte MF, Schafer P, Kurtz J, Bouchardy C: Important increase of invasive lobular breast cancer incidence in Geneva, Switzerland. Int J Cancer 2003;104:778781.

25 Van Steenbergen LN, Voogd AC, Roukema JA, Louwman WJ, Duijm LEM, Coebergh JWW, van de Poll-Franse LV: Screening caused rising incidence rates of ductal carcinoma in situ of the breast. Breast Cancer Res Treat 2009;115:181-183.

26 Malek D, Rabe P, Bock K, Hecht G, Heindel W, Heywang-Köbrunner S, Kettritz U, Regitz-Jedermann L, Katalinic A, Urbschat I: Evaluationsbericht 2005-2007. Ergebnisse des MammographieScreening-Programms in Deutschland. Köln, Kooperationsgemeinschaft Mammographie, 2009, pp 69-72.www.mammo-programm.de/cms_upload/ datenpool/evaluationsbericht05-07_web.pdf. 